\title{
Determinants of old-age mortality in Taiwan
}

\author{
Zachary Zimmer \\ Population Council \\ Linda G. Martin \\ Population Council \\ Hui-Sheng Lin
}

Follow this and additional works at: https://knowledgecommons.popcouncil.org/departments_sbsr-pgy

Part of the Demography, Population, and Ecology Commons, Family, Life Course, and Society Commons, Gerontology Commons, and the International Public Health Commons How does access to this work benefit you? Let us know!

\section{Recommended Citation}

Zimmer, Zachary, Linda G. Martin, and Hui-Sheng Lin. 2003. "Determinants of old-age mortality in Taiwan," Policy Research Division Working Paper no. 181. New York: Population Council. Version of record: https://doi.org/10.1016/j.socscimed.2004.06.006 


\section{Determinants of Old-Age} Mortality in Taiwan

Zachary Zimmer

Linda G. Martin

0

Hui-Sheng Lin

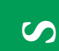

[T]

\&

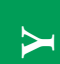

$\mathcal{U}$

$\mapsto$

$\mapsto$

0

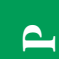

(P) Population Council 


\title{
Determinants of Old-Age Mortality in Taiwan
}

\author{
Zachary Zimmer \\ Linda G. Martin \\ Hui-Sheng Lin
}

Zachary Zimmer is Research Associate and Linda G. Martin is President, Population Council, New York. Hui-Sheng Lin is Director, Center for Population Research, Taiwan Bureau of Health Promotion, Taichung.

An earlier version of this paper was presented at the Annual Meeting of the Population Association of America, Minneapolis, Minnesota, May 1, 2003. The research is supported by a grant (R01 AG20063-01) from the National Institute on Aging. The authors thank Alberto Palloni for his comments. 


\begin{abstract}
Relationships among socio-demographic characteristics, general assessments of health, and old-age mortality are well established in developed countries. There is also an increasing focus on the connection between early-life experiences and latelife health. This paper tests these and other associations using representative survey data from Taiwan on the population aged 60 and older in 1989, 1993, and 1996 that have been linked to data on deaths between 1989 and 1999 from a national death registry. The study also explores the possible influence of Taiwan's Universal Health Insurance Program, instituted in 1995, and whether or not the survival of some groups of older people may have been differentially enhanced. Mortality is modeled using Gompertz regression. Multiple survey waves are employed to construct time-varying covariates. Some results verify findings of past studies; others are new. Effects of education are attenuated after the introduction of some health indicators. Functional and global assessments of health have stronger associations with mortality than do self-reports of health behaviors or particular chronic conditions such as diabetes. Mainlanders have higher survival than others. The survival of older adults with the greatest number and severity of functional limitations improved over the 1990s, suggesting a possible beneficial influence of the insurance program.
\end{abstract}

This material may not be reproduced without written permission from the authors. For a list of Policy Research Division Working Papers, including those available for downloading in PDF format, see www.popcouncil.org/publications/wp/prd/rdwplist.html. 
Most countries of the world are experiencing, or will soon experience, population aging, that is, an increase in the size and proportion of their populations in older ages. Age-structure changes of this sort have been particularly rapid in parts of Asia, where many populations will soon be among the world's oldest (United Nations 2002). These aging societies face a number of related challenges, some of which lead to questions that can be addressed using research on mortality determinants. For example, as populations age, the proportion of mortality that occurs at older ages increases, and questions arise about how old-age mortality varies over time and across different groups. The answers can provide critical insights into the effectiveness of investments to reduce mortality through medical care, behavioral change, and other interventions both early and late in life. The current study examines determinants of old-age mortality in Taiwan, one of the most rapidly aging societies in the world.

Research on adult mortality determinants, to date conducted mostly in developed countries, has highlighted three domains of individual-level characteristics across which old-age mortality tends to vary. First, considerable research demonstrates connections between individual socio-demographic characteristics and old-age mortality (House et al. 1990; Kaplan et al. 1989; Kitagawa and Hauser 1973; Lopez, Caselli, and Valkonen 1995; Preston and Taubman 1994; Valkonen 1989). For instance, it is well established that women have greater survival chances than do men (Waldron 1986). Adults who are married have been found to outlive others throughout the life cycle in both the developed and developing world (Hu and Goldman 1990; Mostafa and Van Ginneken 2000). Also well established is the inverse relationship between socioeconomic status and mortality, which may extend into old age though perhaps in an attenuated form (Valkonen 1989; Preston and Taubman 1994). Education often is used as an indicator of socioeconomic status, since it has the advantage over income of being fixed relatively early in life and is less subject to influence by end-of-life health status.

Second is an increasing focus on early-life disadvantages via exposure to disease or environmental toxins, limited access to prevention (e.g., inoculations) and treatment, living in poverty, and engaging in high-risk occupations (Elo and Preston 1997; Kuh and Ben-Shlomo 1997). Individual-level information on adverse conditions in early life is limited, but socio-demographic measures such as educational attainment, race, and 
ethnicity, which are generally constant throughout life, may serve as indicators of both early-life and late-life conditions that may influence survival. For example, education may reflect genetic endowment, economic resources, access to and ability to optimize use of health care, and perhaps a longer time horizon that results in lower-risk behaviors. Engagement in high-risk behaviors, such as smoking, and other lifestyle characteristics, such as diet, are themselves important indicators of earlier-life experience that can influence late-life survival.

Third, a growing body of evidence — once again, primarily from developed countries - attests to the power of general self-assessments of health in predicting mortality in the near term, even when other, more specific health-risk factors are controlled for (Idler and Benyamini 1997; Benyamini and Idler 1999). Besides reflecting current health status, it could be that such late-life health measures capture a lifetime accumulation of exposures, experiences, and care. Less attention has been given to the predictive power of late-life self-reports of functional limitation or disability. Functional limitation, in general, refers to the ability to carry out basic physical tasks, such as walking, climbing, and lifting (Nagi 1965, 1991). Disability measures focus on how well an individual interacts and functions within social and living environments; examples include so-called activities of daily living (ADL), such as getting out of bed and feeding oneself (Katz et al. 1963), and instrumental activities of daily living (IADL), such as shopping and cooking meals (Lawton and Brody 1969). Liu, Hermalin, and Chuang (1998), Liang et al. (2000), and Liang et al. (2002) include such measures in their models of mortality among elderly Asian populations, but they do not focus on their relative predictive power. Studies in the United States indicate that self-reports of functional limitations and performance tests of functioning may indeed be predictive of mortality. Guralnik et al. (1994) find that in the 1980s they are associated with subsequent mortality in select US populations, and Fried et al. (1998) find that IADL disability predicts mortality in four US communities. A study in Hawaii by Rantanen et al. (2000) indicates that a performance measure of grip strength among middle-aged males is an important predictor of mortality in the long term.

Besides these individual-level characteristics, contemporary access to health care may be another critical determinant of mortality. A major experiment in the United States 
found that reduced use of health care services as a result of cost-sharing did not substantially lead to a deterioration in health for the average person, but the negative effects on the health and predicted mortality of the sickest 6 percent were substantial (Newhouse et al. 1993). Less attention has been paid to this potential mortality determinant primarily because data on mortality and data on health care access and use typically are not available together.

Given the data limitations, all of these determinants of old-age mortality taken together have been investigated much less extensively in non-Western populations than in the West. Notable exceptions in Asia are studies by Liang et al. (2002) for Japan, Liang et al. (2000) for China, and, most relevant for the current analysis, Liu et al. (1998) for Taiwan. All three focus on the socioeconomic gradient in mortality. Determinants considered include age, sex, education, late-life self-assessed health, functional status, as well as chronic or serious illness in the first two studies. All three use a nested approach in which the effects of socio-demographic variables on mortality are assessed both alone and in models that also include intermediate health measures. The idea behind the latter is that socio-demographic variables may influence mortality indirectly through these health measures that are presumed to be more proximate to mortality. The residual effects of the socio-demographic factors in the fuller models reflect their direct effects. All three studies find that more education is associated with lower mortality at older ages, although there is some crossover among the oldest Japanese males, and in China the effects of education on mortality are greater for females than for males. In Taiwan, analysis based on data from 1989 to 1993 showed that education influenced mortality indirectly through measures of late-life health and functional status and behaviors.

In the current paper, we revisit the data used by Liu et al. (1998) and build on their analysis with six additional years of mortality experience from 1993 to 1999; we also explore the effects of early-life circumstances, past health-risk behaviors, and latelife chronic conditions upon which they did not report. The addition of six years of data is valuable not only for providing a longer-term assessment of mortality determinants, but also for allowing indirect assessment of the influence of the change in health care as a result of the introduction in 1995 of Taiwan's Universal Health Insurance Program. 
Previously only about half the population of Taiwan had health insurance, and the new system is believed to have greatly increased the use of both outpatient and inpatient care (Cheng and Chiang 1997; Chiang 1997). It is not known whether such increased use has had any influence on the health and mortality of older Taiwanese, although an earlier study showed some evidence that mortality declined substantially between 1995 and 1999 among those with the most serious functional limitations while remaining constant for others (Zimmer, Martin, and Chang 2002). The initiation of the insurance program came roughly at the mid-point of the three waves of data that we use for the current study, providing in essence a natural experiment of the short-run influence of improved access to health care in late life.

\section{METHODOLOGY}

\section{Data}

The Survey of Health and Living Status of the Elderly in Taiwan, a joint project between the University of Michigan in the United States and the Bureau of Health Promotion in Taiwan, is a representative panel study of elderly Taiwanese. Data collection began in 1989 with 4,049 respondents aged 60 and older. The method of data collection was in-person interviews. The 1989 sample was followed up in 1993 and 1996. The data have been linked to a death register that provides the exact date of death for those who died beginning at the day of initial interview until April 1, 1999, thus offering a rich opportunity to investigate socio-demographic and health status differentials in subsequent mortality. In this paper, we track the survival of the 4,049 respondents over the ten-year period for which death data are available, and we analyze the socio-demographic and health-related determinants of survival using information reported in three survey waves, with information that changes over time being considered as time-varying covariates. (There was a fourth wave-the 1999 followup-but the information from this survey is not included here since mortality has not been followed beyond April 1, 1999.)

The initial interviews were conducted between April 1 and October 23, 1989, with 97 percent taking place in the first two months. Follow-up interviews were con- 
ducted during the same time of year (that is, mostly in April and May of 1993 and 1996). In order to minimize refusals, proxies were used in cases in which the respondent was unable to answer questions, mostly because of health reasons, although proxy responses were restricted to provision of current factual information.

The first survey achieved a 92 percent response rate. Respondents who refused the first follow-up in 1993 were re-contacted in 1996, so a nonresponse for the second wave does not necessarily imply a nonresponse for the third. In fact, more than half of the 306 refusals in 1993 agreed to be interviewed in 1996. Response rates for the 1993 and 1996 surveys were 91 percent and 89 percent. Even if respondents refused or were lost during the ten-year period, their links to the death register were maintained, guaranteeing that mortality and date of death are accurately recorded. By the end of the tenyear period 1,060 adults, or about one-quarter of the original sample, were deceased.

For descriptive purposes, Figure 1 shows patterns of survival by sex and broad age groups over our observation period. As might be expected, older people were more likely to die than younger people. Men were more likely to die than women with the exception of the 80 and older group in which some crossover between the sexes occurs. The highest ten-year survival probability is among women who were 60 to 69 years old in 1989; they have a greater than 80 percent chance of still being alive on April 1, 1999. The lowest probability is among women 80 and older, who had less than a 20 percent chance. These survival patterns are unadjusted for differences in within-group age structure.

One of the reasons for differences in survival by sex could be differences in initial ages. For instance, if men between 60 and 69 were substantially older on average than women 60 to 69 , we would expect mortality to be higher for men. The average initial age within groups is included in the figure. For instance, the average initial age of women 60 to 69 is 64.7 . The initial average ages within the first two age groups (60 to 69 and 70 to 79) do not differ much between men and women. They differ among the 80 and older group by 0.6 years, with men being initially older than women. Therefore, the crossover effect within the 80 and older group and the higher female mortality at some points in the observation period are not accounted for by an older initial age. We do not place too much emphasis on the crossover, however, since the 80 and older group is small and rates of survival are based on few deaths per year. 
Figure 1 Probability of surviving to specific dates by age and sex

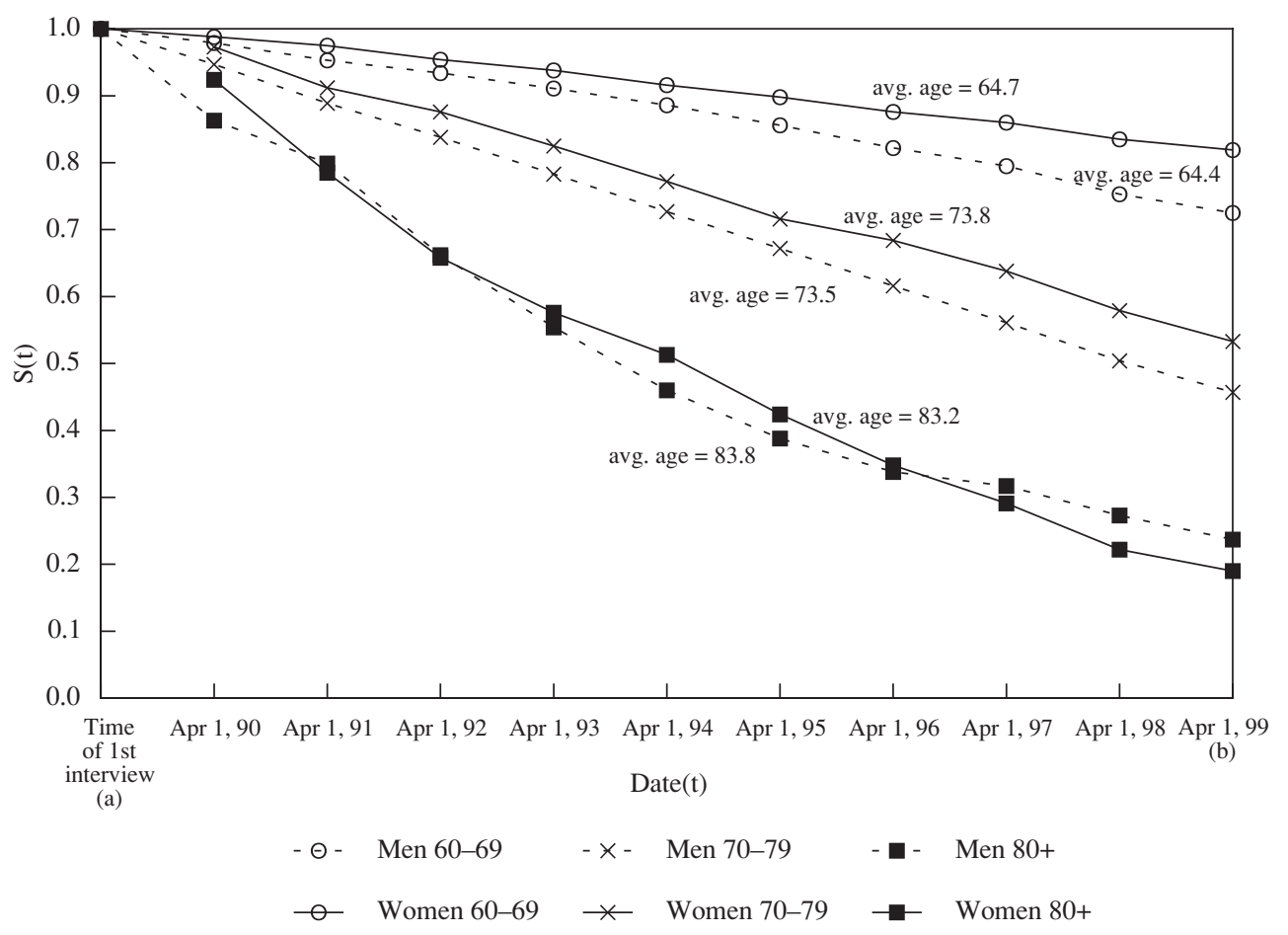

(a) Initial interviews conducted between April 1 and October 23, 1989.

(b) End of observation period. All those surviving to this point are censored.

\section{Measures}

The outcome measure for this study is survival time, which is indicated by registry information on date of death. A series of socio-demographic and health measures are considered as predictors of survival time. Table 1 shows the characteristics of the 4,049 respondents at the time of the initial interview in 1989 using the measures that are included in the models estimating survival.

Socio-demographic measures included are age, sex, marital status, Mainlander status, and education. The young age distribution within the 60 and older population is what one would expect for a population that has only recently begun to age. For our analysis, we use information on date at birth and interview date to calculate exact age in years, which is used as a continuous variable. For 475 cases, information on birth year but not birth date was available; we assumed that the birth date was July 1 . 
Table 1 Description of covariates at initial interview in $1989(\mathrm{~N}=4,049)^{\mathrm{a}}$

\begin{tabular}{|c|c|c|}
\hline Covariate & Percent & Notes \\
\hline \multicolumn{3}{|l|}{ Socio-demographics } \\
\hline Age $60-69$ & 64.6 & Measured continuously for multivariate analysis. \\
\hline Age $70-79$ & 29.2 & Average age of sample is 68.7 in 1989. \\
\hline Age $80+$ & 6.3 & \\
\hline Female & 42.9 & \\
\hline Male & 57.1 & \\
\hline Married & 64.3 & 2 missing cases eliminated from multivariate analysis. \\
\hline Not married & 35.7 & \\
\hline Mainlander & 22.0 & \\
\hline Non-Mainlander & 78.0 & \\
\hline No education & 50.4 & 18 missing cases eliminated from multivariate analysis. \\
\hline Primary education & 30.8 & \\
\hline More than primary & 18.9 & \\
\hline \multicolumn{3}{|l|}{ Health behaviors } \\
\hline Smokes & 34.6 & 1 missing case coded as never smoked. \\
\hline Formerly smoked & 15.2 & \\
\hline Never smoked & 50.2 & \\
\hline Drinks & 21.2 & 5 missing cases coded as never drank. \\
\hline Formerly drank & 15.5 & \\
\hline Never drank & 63.3 & \\
\hline Chews betel nut & 5.4 & 17 missing cases coded as never chewed. \\
\hline Formerly chewed betel nut & 3.8 & \\
\hline Never chewed betel nut & 90.8 & \\
\hline Health conditions & & Missing responses assumed coded as not having condition. \\
\hline Cardiovascular problems & 39.2 & 25 missing cases. \\
\hline Diabetes & 8.4 & 11 missing cases. \\
\hline Stroke & 4.3 & 18 missing cases. \\
\hline Lung problems & 18.5 & 10 missing cases. \\
\hline Gastrointestinal problems & 23.9 & 11 missing cases. \\
\hline Liver disease & 5.9 & 3 missing cases. \\
\hline \multicolumn{3}{|l|}{ Functional status } \\
\hline No functional problems & 38.0 & \\
\hline First quintile & 11.0 & \\
\hline Second & 12.9 & \\
\hline Third & 10.4 & \\
\hline Fourth & 12.8 & \\
\hline Fifth quintile & 14.8 & \\
\hline \multicolumn{3}{|l|}{ Self-assessed health } \\
\hline Excellent & 16.7 & \\
\hline Very good & 21.1 & \\
\hline Good & 36.9 & \\
\hline Fair & 17.9 & \\
\hline Poor & 3.9 & \\
\hline No response & 3.5 & \\
\hline \multirow[t]{2}{*}{ Proxy respondents } & 4.9 & A proxy was the one person who knew respondent best. \\
\hline & & $\begin{array}{l}\text { Percent of proxy respondents was } 6.1 \text { and } 9.3 \text { in the } 1993 \text { and } 1996 \\
\text { surveys respectively. }\end{array}$ \\
\hline
\end{tabular}

${ }^{a}$ The following variables were tested and dropped owing to lack of significance: current rural/urban residence, rural/urban residence growing up, father's education, father's early death, mother's early death, did not respond to follow-up interview. 
Unlike older populations elsewhere, a majority of the Taiwan sample is male. Almost two-thirds of the sample is married, and almost a quarter was born in Mainland China. Most of the "Mainlanders" arrived in Taiwan in the late 1940s after the revolution in China. Mainlanders tend to be male and former soldiers; they are less likely to have ever married and are more likely to have held jobs that provided health insurance throughout their lives than others in Taiwan. Thus, this variable provides some indication of living conditions before reaching old age. About half of the sample has no education and less than 20 percent has more than primary. Two cases without information on marital status and 18 cases without information on educational attainment were excluded from the analysis.

In our preliminary analysis, we investigated several other socio-demographic measures. First, we tested urban/rural residence, but found no significant effects in any of our models of mortality. Next, we examined early-life conditions in addition to education and origin on the Mainland - namely, father's education, urban/rural residence when growing up, early death of father, and early death of mother. There was a great deal of item-nonresponse for all of these measures, including nonresponse associated with use of proxies. For the responses that did remain, we found little relationship with mortality. In the end, we did not retain any of these variables in our models.

As for health measures, we begin with a number of health behaviors that can have life-long influences on old-age mortality. For instance, we expect smokers and those who chew betel nut to have lower survival rates than those who never used these products, whereas alcohol consumption may have positive effects. The prevalence of cigarette smoking increased substantially after World War II, reached a plateau in the 1960s, and is now one of the most important health problems in Taiwan (Liaw and Chen 1998). Table 1 shows that over a third of the sample are current smokers as of 1989, and 15 percent are former smokers. About a fifth of the sample reports drinking alcohol, and 16 percent are former drinkers. Fewer are current or former betel nut chewers. A small number of cases are without these pieces of information and are coded as never having engaged in these behaviors.

Next, we included a series of measures that signify current health status. The first several indicate whether or not individuals reported various health conditions. The specific question asks: "Do you have any of the following at the present time?" Cardiovas- 
cular problems, based on questions about high blood pressure, high cholesterol, and heart trouble, are the most common self-reported condition. The next most common is gastrointestinal problems, which include ulcers, stomach disorders, and other digestive tract disorders. Lung problems refer to asthma, emphysema, bronchitis, tuberculosis, and other lower respiratory tract diseases. Liver disease covers liver or gall bladder problems. Finally, we include diabetes and stroke as single items. Several other conditions included in the survey are not considered because they represent symptoms (for example, experiencing dizziness), they are not directly related to mortality (for example, hemorrhoids), or they are items not repeated in later interviews. The small number of respondents who did not reply to these questions are coded as not having the condition for purposes of our analysis. It is important to note that responses to these questions may reflect a true underlying problem, access to health care and thus diagnosis, or misinformation. Thus, there may be considerable measurement error.

Possibly more reliable are self-reports of functional limitation and disability. Survey questions ask about the ability to carry out normal daily tasks, such as walking a given distance or bathing. These types of items are often categorized as activities of daily living or instrumental activities of daily living (Katz et al. 1963; Lawton and Brody 1969) or as Nagi measures of functional limitation (Nagi 1965, 1991). Respondents were asked about 13 such items in 1989 (bathing, making a telephone call, shopping, managing money, riding the bus or train, doing physical work around the house, standing two hours, squatting, raising arms, grasping, lifting, walking 200-300 meters, and walking up two or three flights of stairs); and for each, respondents were asked whether they could perform the task without difficulty, with a little difficulty, with a lot of difficulty, or not at all. Additional items were added to the survey between the first and subsequent interviews, and, unfortunately, the wording of questions changed. We continued to use only the original 13 activities, but arrayed respondents within each wave into rough ordinal groupings using an index of functional status. To create the index we first scored responses for each individual activity from 0 (no difficulty) to 3 (cannot perform the task). We then summed the scores for the 13 items. If there were missing responses on one or more items, we summed the scores for items that were answered. We then divided the sum by the number of items answered, creating an index ranging from 0 (no functional problems) to 3 (cannot do any of the items). From these scores, we 
created six categories for each survey wave. The first represents those without difficulty. For the next five, we divided the remaining scores as closely as possible into quintiles. The result is that for 1989, 38 percent have no problems, 11 percent have the fewest number and severity of limitations (first quintile), about 13 percent have a slightly higher level of limitation (second quintile), and so on, with each of the categories of people with limitations consisting of 10 to 15 percent of respondents.

The next measure of health is a global self-assessment based on a question that asks respondents to rate their overall health as excellent, very good, good, fair, or poor. Besides these five categories, a not insubstantial proportion (3.5 percent) did not answer this question, and we added a category to capture these nonrespondents. Many of these missing responses were actually from cases for which proxy respondents could not provide a self-assessment of health, and we thus presume that the nonrespondent category is made up of many who are in fairly poor health or have cognition problems and therefore could not participate directly in the survey. Almost 40 percent of respondents describe their health as excellent or very good in 1989.

Finally, we included a variable for whether or not a proxy answered for the respondent. Proxies were used in the case of respondents' severe illness, hospitalization, emotional disturbance, mental impairment, hearing impairment, or illiteracy. Proxies were not used for persons temporarily absent or otherwise unavailable. Because proxy responses were given mainly in the case of health-related absences, this measure is, in a way, an indicator of poor health. In 1989, 4.9 percent of the interviews were conducted with proxies. Among survivors to the later waves, the proxy response rates for 1993 and 1996 were 6.1 percent and 9.3 percent.

In addition, we tested but ultimately dropped a variable that coded whether a respondent did not respond to a particular follow-up wave of the survey. Nonresponse might have been important because of the way we constructed our time-varying covariates (to be discussed below). However, it ended up not being a significant predictor of survival, and its inclusion did not alter the results we provide herein.

\section{Predicting survival}

We examine the survival of elderly Taiwanese between April 1, 1989 and April 1, 1999 by fitting a series of nested maximum likelihood regression models using the 
Gompertz hazard distribution, which assumes an exponential change in the mortality hazard with duration of exposure or time (Finch and Pike 1996; Franses 1994; Lee and Wang 2003; Wilson 1994). The distribution has been employed often in studies of oldage mortality because it fits human mortality to older ages quite effectively and implies a one-dimension failure process (Haybittle 1998; Manton et al. 1994; Mueller, Nusbaum, and Rose 1995). The hazard distribution assumes an underlying instantaneous rate of mortality that is monotonically increasing or decreasing with duration of exposure. The model can be described as:

$$
h(t)=\lambda e^{\alpha t},
$$

where $h(t)$ is the instantaneous hazard of dying at an exact time $t, \lambda=e^{\chi \beta}$, and $\alpha$ represents the force of mortality. Since our data record the date but not exact moment of death, for our purposes we are gauging the hazard of dying on a given day. $\lambda$ represents the level of mortality and is estimated by a vector of covariates $(x)$, which in our study includes age at the start of an observation period, other socio-demographic characteristics, health behaviors, and health status measures, multiplied by their coefficients $(\beta)$. $\alpha$, also estimated by the data, is fixed for each individual regardless of his or her characteristics. If $\alpha$ equals zero, the hazard function becomes equal to $\lambda$, that is, there is no increasing or decreasing hazard with duration of exposure. If $\alpha$ is positive, then the hazard of dying increases with duration.

We tested the appropriateness of this specification in two ways. First, plots of residuals indicated a good fit. Second, we compared a simple model that included a variable representing age measured in days from the initial observation of the entire sample (April 1, 1989) and compared the baseline hazard $(\alpha)$ to one that constrained the coefficient of age to be equal to the baseline hazard; we found no statistically significant difference between the two, thus verifying that the Gompertz specification is an appropriate baseline hazard function for our data.

Some of the socio-demographic characteristics, such as sex and education, do not change over time, but others do. For instance, an individual who is married at one point in time may become widowed at a later date while still under observation. All of the health characteristics are, of course, subject to change with time. That is, an individual may develop a health problem or may recover from one. Similarly, proxy response may vary from 
wave to wave. Since these measures potentially change over time, our Gompertz equation includes some time-varying covariates. Unfortunately, we do not have information on the exact day of a change in a covariate. Thus, we make use of the data provided from the most recent observation. For instance, in estimating mortality from 1989 to 1993, we take data on the predictors from the 1989 survey wave. If the respondent or his/her proxy provided data in 1993 and/or 1996, we use information from the follow-up beginning on the day of the interview. For those who refuse the follow-ups or are lost over time, we use data from the latest survey wave to which there is a response. The time-varying covariates are employed by dividing the observation of a single respondent into periods that begin at the time of an interview.

We employ a nested strategy for estimation, with initial models controlling simply for age and sex; we then add other socio-demographic factors, then the various health measures in groups, and finally we estimate a full model with all covariates included. This approach allows us to use chi-square tests to analyze the extent to which the addition of blocks of variables contributes to the prediction of mortality. It also facilitates assessment of the direct and indirect effects of socio-demographic variables. If a given variable has a significant effect on mortality in the model in which only socio-demographic variables are included, but that effect is diminished in size while persisting in statistical significance in fuller models including health measures, then the socio-demographic variable is related to mortality both directly and indirectly. If the effect of the socio-demographic variable does not change, then the direct effect is robust. If the effect is eliminated, then the effect of the variable on mortality is entirely indirect.

\section{Effect of pre- versus post-insurance periods}

Our study not only examines the association between individual-level socio-demographic and health covariates and old-age mortality, but also explores whether there might be an additional influence of the Universal Health Insurance Program initiated in 1995. We first look at the average unadjusted annual death rates in pre- and post-insurance periods by age and sex. Because our sample begins in 1989 at age 60 and older, our respondents were aged 66 and older by the time the insurance program came into effect. Hence, for our initial comparison, we limit the sample to those aged 66 and older. 
We then examine the possible effect of insurance in multivariate models using the entire 60-and-older sample by including a variable for pre- versus post-insurance periods. This measure is created by coding as 0 any observation time before April 1, 1995, the day the program came into effect, and as 1 afterward. In total, the ten-year observation period is split into a maximum of four observation periods, depending upon how long an individual survives: 1) from initial interview date in 1989 to re-interview date in 1993; 2) from interview date in 1993 to March 31, 1995; 3) from April 1, 1995 to next re-interview date in 1996; 4) from interview date in 1996 to April 1, 1999. Cases observed in periods 1 and 2 will have codes of 0 for pre/post insurance, while cases observed in periods 3 and 4 will have codes of 1 . Our final steps involve running interaction models to determine whether the influence of any of the covariates differs between pre- and post-insurance periods and then fitting models on selected subsamples.

\section{RESULTS}

\section{Health and socio-demographic effects on mortality}

Table 2 presents the results from models that include socio-demographic characteristics only. In the first, including only age and sex, older people and males have higher mortality. For instance, a coefficient of -.269 for females indicates that their probability

Table 2 Gompertz hazard models testing socio-demographic effects

\begin{tabular}{|c|c|c|}
\hline & Model 1 & Model 2 \\
\hline & Age + sex & $\begin{array}{c}\text { Age }+ \text { sex }+ \\
\text { other socio-demographics }\end{array}$ \\
\hline Age & $.095 * *$ & $.085^{* *}$ \\
\hline Female & $-.269 * *$ & $-.489 * *$ \\
\hline Married & & $-.301 * *$ \\
\hline Mainlander & & $-.255^{* *}$ \\
\hline Primary education & & $-.184 * *$ \\
\hline More than primary & & $-.302 * *$ \\
\hline Constant & -16.04 & -14.83 \\
\hline$\alpha$ & .00034 & .00032 \\
\hline Log-likelihood & -5489.8 & -5459.3 \\
\hline$\Delta-2 \mathrm{LL}$ & $661.7 * * \mathrm{a}$ & $60.9 * * \mathrm{~b}$ \\
\hline
\end{tabular}


of dying is $e^{-.269}$ or 0.76 times that of males. A positive value for $\alpha$ confirms an increasing hazard of dying with duration of observation. The second model shows the expected patterns after adding marital status, Mainland origin, and education. Those married, from the Mainland, and with more education have lower mortality and hence survive longer. Although the first and last of these effects are similar to what has been found in other studies, the effect of being a Mainlander is novel. It suggests that immigrants from Mainland China may be a select group, physically healthier than others, perhaps owing to their early-life experiences or their better access to the health care system in comparison to most Taiwanese during their working years.

In the next set of models (Table 3), we add the health measures to the last model of Table 2. The first adds health behaviors, the next three add the health status variables, and the penultimate model adds the indicator of whether or not the response was provided by a proxy respondent. The last model includes all health and socio-demographic covariates. Our discussion of the results will review the individual health models and the full model simultaneously.

In general, the health measures are associated with subsequent mortality in the expected ways. For example, being a current or former smoker or a current betel nut chewer is positively related to mortality. In contrast, being a current drinker is protective. One wonders whether the positive coefficient on former drinking results from the cessation of drinking by those with health problems, otherwise unmeasured. Indeed, in the full model with all the health measures, the effect of being a former drinker is no longer significant. The same is the case for being a former smoker.

The reporting of four of the six health conditions—cardiovascular problems, diabetes, stroke, and lung problems - is also strongly and significantly related to the hazard of dying. In the full model with all the health measures, only diabetes and lung problems continue to have significant positive effects on mortality.

The coefficients on the quintile rankings of functional status are positive and significant, indicating that persons with limitations at a prior survey wave were more likely to die than those with no limitations (the omitted category). A greater number of limitations is generally associated with a greater risk of dying. The one exception is that the second least limited group seems to have a slightly lower risk of dying than the least limited group, although the coefficients for these two groups are not significantly differ- 
Table 3 Gompertz hazard models testing health effects

\begin{tabular}{|c|c|c|c|c|c|c|}
\hline & Model 3 & Model 4 & Model 5 & Model 6 & Model 7 & Model 8 \\
\hline & $\begin{array}{c}\text { Health } \\
\text { behaviors }\end{array}$ & $\begin{array}{c}\text { Health } \\
\text { conditions }\end{array}$ & $\begin{array}{c}\text { Functional } \\
\text { status }\end{array}$ & $\begin{array}{c}\text { Self-assessed } \\
\text { health }\end{array}$ & Proxy & $\begin{array}{c}\text { Full } \\
\text { model }\end{array}$ \\
\hline \multicolumn{7}{|l|}{ Socio-demographics } \\
\hline Age & $.083 * *$ & $.086^{* *}$ & $.055^{* *}$ & $.070 * *$ & $.072 * *$ & $.060 * *$ \\
\hline Female & $-.330 * *$ & $-.495 * *$ & $-.701 * *$ & $-.530 * *$ & $-.482 * *$ & $-.486 * *$ \\
\hline Married & $-.293 * *$ & $-.306 * *$ & $-.276 * *$ & $-.251 * *$ & $-.284 * *$ & $-.262 * *$ \\
\hline Mainlander & $-.204 * *$ & $-.284 * *$ & $-.193 *$ & $-.213 * *$ & $-.227 * *$ & $-.167 *$ \\
\hline Primary education & $-.202 * *$ & $-.166^{*}$ & -.032 & -.101 & $-.144 *$ & -.034 \\
\hline More than primary & $-.269 * *$ & $-.282 * *$ & -.058 & -.117 & $-.272 * *$ & -.020 \\
\hline \multicolumn{7}{|l|}{ Health behaviors } \\
\hline Never smoked & - & & & & & - \\
\hline Smokes & $.228 * *$ & & & & & $.296 * *$ \\
\hline Formerly smoked & $.254 * *$ & & & & & .124 \\
\hline Never drank & - & & & & & - \\
\hline Drinks & $-.466^{* *}$ & & & & & $-.244 * *$ \\
\hline Formerly drank & $.199 * *$ & & & & & .104 \\
\hline Never chewed betel nut & - & & & & & - \\
\hline Chews betel nut & $.293 *$ & & & & & $.251^{*}$ \\
\hline Formerly chewed betel nut & .127 & & & & & .039 \\
\hline \multicolumn{7}{|l|}{ Health conditions } \\
\hline Cardiovascular problems & & $.125^{*}$ & & & & .034 \\
\hline Diabetes & & $.694 * *$ & & & & $.534 * *$ \\
\hline Stroke & & $.889 * *$ & & & & .137 \\
\hline Lung problems & & $.424 * *$ & & & & $.237 * *$ \\
\hline Gastrointestinal problems & & .049 & & & & -.091 \\
\hline Liver disease & & .173 & & & & .117 \\
\hline \multicolumn{7}{|l|}{ Functional status } \\
\hline No problems & & & - & & & - \\
\hline First quintile & & & $.438 * *$ & & & $.336 * *$ \\
\hline Second & & & $.346 * *$ & & & .172 \\
\hline Third & & & $.791 * *$ & & & $.518 * *$ \\
\hline Fourth & & & $1.024 * *$ & & & $.654 * *$ \\
\hline Fifth quintile & & & $1.805 * *$ & & & $1.189 * *$ \\
\hline \multicolumn{7}{|l|}{ Self-assessed health } \\
\hline Excellent & & & & - & & - \\
\hline Very good & & & & $.260 *$ & & .078 \\
\hline Good & & & & $.590 * *$ & & $.274 *$ \\
\hline Fair & & & & $1.004 * *$ & & $.378 * *$ \\
\hline Poor & & & & $1.864 * *$ & & $.846^{* * *}$ \\
\hline No response & & & & $1.805^{* *}$ & & $1.018 * *$ \\
\hline Proxy respondents & & & & & $1.060 * *$ & .022 \\
\hline Constant & -14.93 & -15.29 & -13.41 & -14.67 & -14.05 & -14.26 \\
\hline $\begin{array}{l}\alpha \\
\text { Log-likelihood }\end{array}$ & $\begin{array}{r}.00034 \\
-5421.5\end{array}$ & $\begin{array}{r}.00036 \\
-5326.5\end{array}$ & $\begin{array}{r}.00028 \\
-5186.3\end{array}$ & $\begin{array}{r}.00037 \\
-5227.8\end{array}$ & $\begin{array}{l}.00033 \\
5364.1\end{array}$ & $\begin{array}{r}.00036 \\
-5070.4\end{array}$ \\
\hline$\Delta-2 \mathrm{LL}^{\mathrm{a}}$ & $75.6 * *$ & $265.7 * *$ & $546.1 * *$ & $463.0 * *$ & $190.4 * *$ & $777.8 * *$ \\
\hline
\end{tabular}

$* .05>\mathrm{p}>.01 * * .01>\mathrm{p}$

${ }^{\mathrm{a} C}$ Compared to model 2 with socio-demographics 
ent from each other. The effects of functional status remain strong even after controlling for all the other health measures - once again with the exception of the second quintile. In addition, there appears to be a substantial increase in the risk of dying between those in the fourth quintile and those with the most serious problems. Those in the fifth quintile clearly have very high mortality risks.

Self-assessed health also has expected effects both in the model in which it is added alone to the socio-demographic variables and in the full model with all the health measures. In the latter, the effect on the probability of dying among those reporting very good health is no longer significantly different from those reporting excellent health (the omitted category). Interestingly, those in the nonresponse category have very high risks of dying that are similar to those in the poor category, reinforcing the suspicion that many of the nonrespondents on this measure have substantial health problems.

The final health model looks at proxy respondents. The proxy variable, on its own, is highly predictive of mortality. When included with all the health variables, however, the effect is minimized, likely because the proxy variable shares much of its variance with all the other health variables. That is, observations based on proxy responses are generally for individuals with poor health across all health measures.

The models provide several other insights. First, the socio-demographic effects remain significant after controlling for health. The exception is the effect of education, which is no longer associated with mortality when all other factors are taken into consideration. Note that this effect is lost when functional status or self-assessed health is added individually in the earlier models. Second, the change in the $-2 \mathrm{X}$ log-likelihood, which is distributed as chi-square, indicates that as a group, each set of health predictors significantly adds to the predictive power of the models. The functional status variables as a group are the most powerful predictors, followed by the self-assessed health measures.

\section{Influence of the post-insurance period on old-age mortality}

The Universal Health Insurance Program was introduced on April 1, 1995. Table 4 shows average unadjusted annual death rates per 1,000 population in the pre- and post-insurance periods by sex and within four broad age groups. On balance, the table shows a fairly substantial decline in death rates among women ages 70 and older and 
Table 4 Average annual death rates per 1,000 population in pre- and post-insurance periods, by age and sex

\begin{tabular}{cccc}
\hline & $\begin{array}{c}\text { Pre-insurance } \\
\text { April 1, 1989 } \\
\text { to }\end{array}$ & $\begin{array}{c}\text { Post-insurance } \\
\text { April 1, 1995 } \\
\text { to } \\
\text { March 31, 1995 }\end{array}$ & $\begin{array}{c}\text { March 31, 1999 } \\
\text { Percent } \\
\text { change }\end{array}$ \\
\hline Males & & & \\
66 to 69 & 27.4 & 24.5 & -10.8 \\
70 to 74 & 41.0 & 44.1 & +7.4 \\
75 to 79 & 68.3 & 63.5 & -6.9 \\
80 and older & 125.9 & 102.5 & $-18.6^{*}$ \\
Females & & & \\
66 to 69 & 14.8 & 18.8 & +26.7 \\
70 to 74 & 29.3 & 18.9 & $-35.3^{*}$ \\
75 to 79 & 62.1 & 46.4 & $-25.3^{*}$ \\
80 and older & 113.8 & 95.9 & $-15.7^{\wedge}$ \\
\hline
\end{tabular}

$\wedge .10>\mathrm{p}>.05 * .05>\mathrm{p}>.01$

a Significance test is a t-test for difference in proportions

among men ages 80 and older. The greatest change in death rates was a 35 percent decline among women aged 70 to 74 years.

On the surface, the changes in death rates in the pre- and post-insurance periods might suggest that any additional health-care access facilitated by the Universal Health Insurance Program serves to decrease mortality. However, we conducted a number of analyses that indicate that mortality decline after 1995 is only modest for the entire older population and, in fact, is concentrated within a particular group. We began by adding to each of the models presented in Tables 2 and 3 a variable indicating whether the at-risk period was pre- or post-April 1, 1995, and we present coefficients for this variable in Table 5. In general, the risk of mortality was significantly lower after April 1, 1995. For instance, in a model containing age and sex, the coefficient for the postinsurance period variable is $-.136(.05>\mathrm{p}>.01)$. Addition of the other socio-demographic variables, health behaviors, and health conditions weakened this effect, and statistical significance became marginal $(.10>\mathrm{p}>.05)$. In the model with functional status, the effect was eliminated statistically; but in the model with self-assessed health, the effect was strongly negative. In the full model, the effect of pre- and post-1995 disappeared. In 
Table 5 Gompertz coefficients for post-April 1, 1995 period across models

\begin{tabular}{clc}
\hline & \multicolumn{1}{c}{ Covariates } & Post-April 1, 1995 \\
Model & \multicolumn{1}{c}{$\boldsymbol{\beta}$} \\
\hline 1 & Insurance + age + sex & $-.136^{*}$ \\
2 & Model 1 + Other socio-demographics & $-.097^{\wedge}$ \\
3 & Model 2 + Health behaviors & $-.108^{\wedge}$ \\
4 & Model 2 + Health conditions & $-.108^{\wedge}$ \\
5 & Model 2 + Functional status & .090 \\
6 & Model 2 + Self-assessed health & $-.167^{* *}$ \\
7 & Model 2 + Proxy respondent & $-.104^{\wedge}$ \\
8 & Full model & -.013 \\
\hline
\end{tabular}

$\wedge .10>\mathrm{p}>.05 \quad * .05>\mathrm{p}>.01 \quad * * .01>\mathrm{p}$

general, the effects of other variables were not changed by the addition of this variable to any of the models.

Next, we explored the use of other years as cut-points (e.g., April 1, 1996; results not shown here but available from the authors upon request), since there could be a lag in the effect of insurance and increased health-care access on mortality. Or it could be that the pre/post categorization is simply picking up a longer-run secular trend in mortality. When we use 1996 or 1998 rather than 1995 as the cut-point, the results are similar to those for 1995. Using 1992, 1993, 1994, or 1997 as the cut-point does not yield statistically significant $(\mathrm{p}<.05)$ results for the period effect in the two socio-demographic models or the full model. Thus, the general, but not universal, result in the simpler models is a significant decline in mortality when comparing 1995 or later years to earlier years, but the period effect disappears in the full models.

To examine whether decline is consistent across groups or whether some groups benefited more than others, we ran interaction effects between the pre- and post-April 1995 indicator and all other covariates. We tested these interactions group by group (as defined in earlier models in Tables 2 and 3), building on the full model plus the period indicator (that is, Model 8 from Table 5). The results are too numerous to present in tabular form, so we mention only the one for which the group of interacted variables significantly added to the predictive power of the full model. We found a strong negative coefficient on the interaction between the post-insurance period and the indicator for the quintile with the most functional limitations, $-.338(\mathrm{p}<.01)$, indicating that the 
risk of dying was substantially reduced after the establishment of the Universal Health Insurance Program among those who previously had reported the greatest number and severity of functional limitations and disabilities. A favorable shift for those with the most limitations may reflect differential increased access to health care, or it may indicate some other concurrent change.

To illustrate this effect, Figure 2 shows the probabilities of dying in different oneyear periods between April 1, 1989 and March 31, 1999, determined from a discretetime hazard model that includes age and year of observation as covariates and that is fit separately for each functional group. Results are shown for those without limitation, the aggregation of those in the first four quintiles (combined because the individual quintile patterns overlapped considerably), and those in the fifth quintile (those with the most

Figure 2 One-year age-adjusted probabilities of dying by time for three functional status groups, estimated from discrete-time hazard models

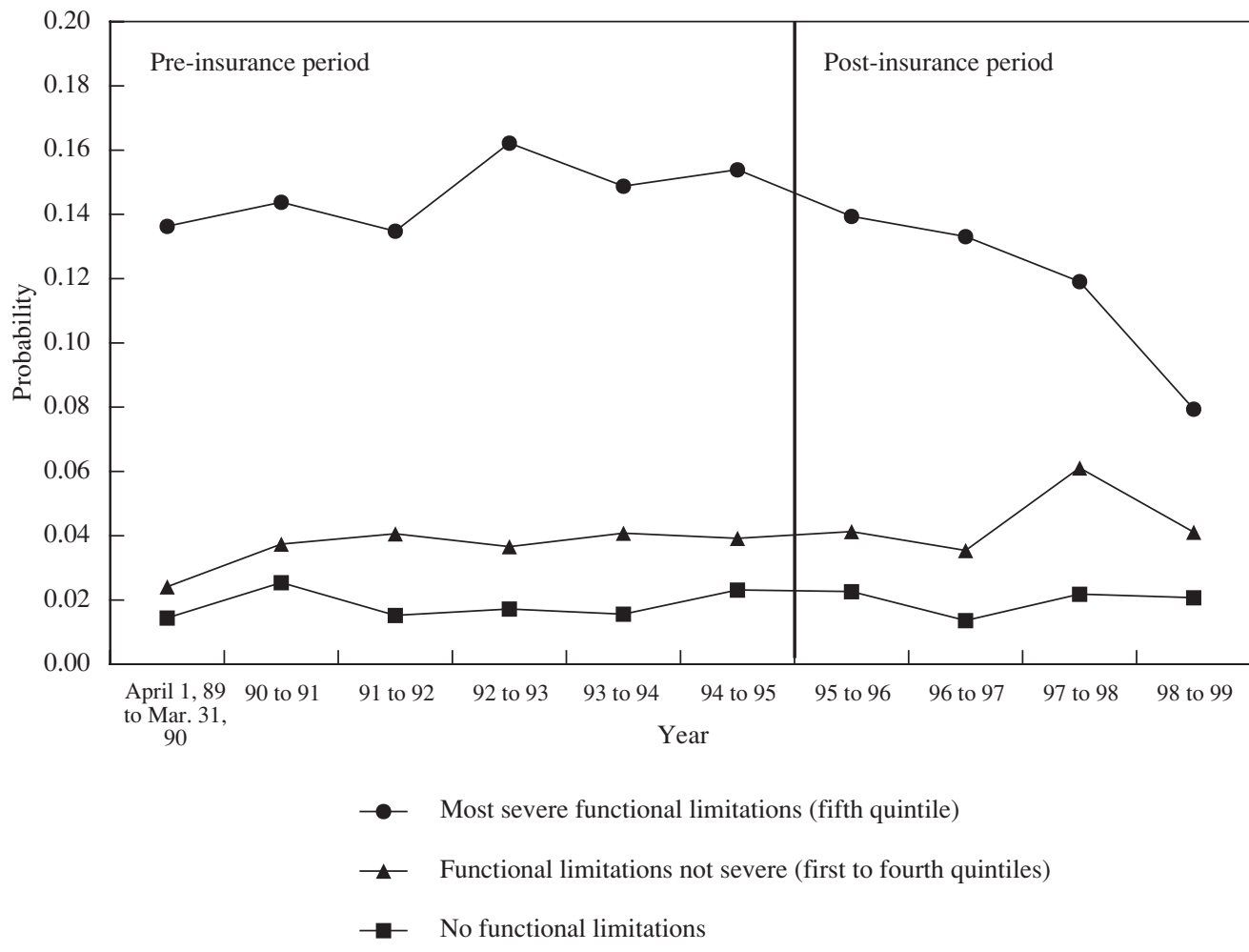


severe and greatest number of limitations). Clearly, those with the greatest number and severity of limitations have the highest probabilities of dying, but they have experienced the greatest decline over time in that risk. The figure does not indicate much of a trend for the other two groups.

Finally, using the Gompertz specification and trying the different period cut-points, we estimated the two socio-demographic models and the full model for these three groups separately (results not shown here but available from the authors upon request). For individuals with no functional problems, we found no statistically significant $(\mathrm{p}<.05)$ period effects. For those in quintiles one to four, the results generally indicate an increase in mortality over time, although the effects are dampened in the full model. For the fifth quintile, the coefficients for the various year cut-points from 1995 on are statistically significant and strongly negative, with the period effects enhanced in the full model. Thus, the socio-demographic and health variables in our models, both fixed and time-varying, are not able to explain the improvement in survival for the most functionally limited group.

\section{DISCUSSION}

Primarily because of rapid declines in fertility over the last 30 years, the proportion of the elderly in Taiwan is expected to more than double over the next three decades. By around 2040, more than one in four Taiwanese will be aged 60 or older, a situation that calls for research helpful in planning and policy development in advance of these rapid changes in age structure (Hermalin and Meyers 2002; Knodel, Ofstedal, and Hermalin 2002). In the current paper, we examined individual-level determinants of mortality among older Taiwanese as well as the changes in mortality that may have occurred since the implementation of a Universal Health Insurance Program. In summary, we find that, from 1989 to 1999 , there is an education gradient in mortality, and the self-assessed general health and functioning measures are highly predictive of survival. We also find survival to be higher among women, Mainlanders, those married, and those who have never smoked or chewed betel nut. Survival is higher among current alcohol drinkers, but lower among former drinkers. Of course, given the limitation of the variables in our data set, we have not been able to explain all of the variation in 
mortality, though what we are able to explain is substantial. A number of our findings support previous research cited earlier, the vast majority of which has been conducted in developed countries, but several findings are more novel.

One notable result is that education's positive effect on survival remains when controlling for health behaviors or specific conditions, although the size of coefficients on education is reduced. However, education loses significance in models including functional status or self-assessed health. These two health measures and education appear to be related to mortality in similar ways.

The predictive power of self-assessed health is consistent with a substantial body of international evidence (Idler and Benyamini 1997; Benyamini and Idler 1999). The finding that functional status is highly predictive of mortality, to our knowledge, has been previously noted only in the United States. It is, however, one worth pursuing. Self-reports of functional task performance are common in surveys of older adults around the world, and as such there is great potential to examine this link further. Like self-assessed health, a functional status measure may indicate health in a broad sense. The measure for the current study was an index of 13 items that reflect the ability both to conduct basic bodily movements and to function within social and living environments. The presence or absence of these capabilities may be linked to specific medical conditions, although they may also be the result of unspecified underlying disorders and distinct combinations of disorders that affect physical, mental, and emotional capacity. The results suggest that those who are more physically active and able are likely to live longer than others.

It is also noteworthy that subjective reports of general health and functioning are overall stronger predictors of mortality than self-reports of specific medical conditions, such as having heart disease or diabetes. One possible reason for this difference is that self-reports of general health and functioning may be more reliable assessments of health status, because many of the specific medical conditions can be asymptomatic or differentially diagnosed. Changes in access to health care and in expectations about health that may occur with changes in health policy or broader socioeconomic development may influence self-reports. But it could also be that subjective aspects of health and functioning are better barometers of and are more sensitive to qualitative changes that reflect overall health and well-being. 
We also witnessed an improvement in mortality over the ten-year observation period, although this change was largely confined to those with the greatest number and severity of functional limitations. We can only speculate on the reason for this pattern-for example, it may be an indication that even a late-life increase in access to health care has enhanced survival. However, given our current data and the relatively short time span, we cannot ascertain whether the decline in mortality following April 1, 1995 is indeed a consequence of the health insurance program or whether other causal mechanisms are at work. For example, the decline in mortality may be simply coincidental or the result of an accumulation of longer-term changes that we cannot measure. Future waves of survey and death registry data will be valuable in verifying this pattern and further exploring its causes. There is certainly a unique opportunity in Taiwan to examine the effect of a major policy decision on health outcomes. The cost and costeffectiveness of such an intervention also remain to be documented, and substantially more work on actual health-care use and interventions related to specific conditions needs to be done.

As just noted, the short time span of ten years covered by this study is a weakness. Taiwan recently has undergone dramatic socioeconomic and public health changes. The period 1989-99 may prove to be exceptional in a number of ways. Older people in Taiwan today have witnessed great transformations during their lifetimesnot the least of which is the epidemiological transition from the predominance of infectious and parasitic diseases to chronic and degenerative diseases. Early in their lives they may have been exposed to much higher levels of infection than are young people today, and no doubt they, on average, experienced much lower standards of living. Unfortunately, our efforts to ascertain the effects of early-life factors on latelife mortality were hampered by high item-nonresponse rates, thus only education and Mainland origin were assessed. The finding that survival is greater for Mainlanders is new, but we can only speculate about how their early-life experiences, possible positive selection for military service, and subsequent work lives and access to health care have led to this result.

Despite these weaknesses, the current study adds to our understanding of old-age mortality in a non-Western setting and provides insights that can be helpful for Taiwan as it looks toward a shift in its population age structure. The elderly of Taiwan one to 
two decades from now may be quite different from those of today. Most easily predicted is the steep rise in the educational attainment of the older population (Christenson and Hermalin 1991). Thus, assuming that more education continues to be strongly associated with greater survival - a relationship that continues to hold in richer countriesthen, all things equal, Taiwan can expect declines in old-age mortality.

\section{REFERENCES}

Benyamini, Y., E.L. Idler. 1999. "Community studies reporting association between selfrated health and mortality: Additional studies, 1995 to 1998." Research on Aging 21:392-401.

Cheng, S.H., T.L. Chiang. 1997. "The effect of universal health insurance on health care utilization in Taiwan: Results from a natural experiment." Journal of the American Medical Association 278:89-93.

Chiang, T.L. 1997. “Taiwan's 1995 health care reform.” Health Policy 39:225-239.

Christenson, B.A, A.I. Hermalin. 1991. "Comparative analysis of the changing educational composition of the elderly population in five Asian countries." Comparative Study of the Elderly in Asia Research Reports. Population Studies Center, University of Michigan, No. 91-11.

Elo, I.T., S.H. Preston. 1997. "Effects of early-life conditions on adult mortality: A review." Population Index 58(2):186-212.

Finch, C.E., M.C. Pike. 1996. "Maximum life span predictions from the Gompertz mortality model." Journal of Gerontology: Biological Sciences 51:B183-B194.

Franses, P.H. 1994. "Fitting a Gompertz curve." Journal of the Operational Research Society 45:109-113.

Fried, L.P., R.A. Kronmal, A.B. Newman, D.E. Bild, M.B. Mittelmark, J.F. Polak, J.A. Robbins, J.M. Gardin for the Cardiovascular Health Study Collaborative Research Group. 1998. "Risk factors for 5-year mortality in older adults: The Cardiovascular Health Study." Journal of the American Medical Association 279: 585-592.

Guralnik, J.M., E.M. Simonsick, L. Ferrucci, R.J. Glynn, L.F. Berkman, D.G. Blazer, P.A. Scherr, R.B. Wallace. 1994. "A short physical performance battery assessing lower 
extremity function: Association with self-reported disability and prediction of mortality and nursing home admission." Journal of Gerontology 49: M85-M94.

Haybittle, J.L. 1998. "The use of the Gompertz function to relate changes in life expectancy to the standardized mortality ratio." International Journal of Epidemiology 27:885-889.

Hermalin, A.I., L.G. Meyers. 2002. "Aging in Asia: Facing the crossroads.” In Hermalin A.I., ed., The Well-Being of the Elderly in Asia: A Four-Country Comparative Study. Ann Arbor, MI: The University of Michigan Press. Pp. 3-24.

House, J.S., R.C. Kessler, A.R. Herzog, R.P. Mero, A.M. Kinney, M.J. Breslow. 1990. “Age, socioeconomic status, and health.” The Milbank Quarterly 68(3):383-411.

Hu, Y., N. Goldman. 1990. "Mortality differentials by marital status: An international comparison.” Demography 27(2):233-250.

Idler, E.L., Y. Benyamini. 1997. "Self-rated health and mortality: A review of 27 community studies." Journal of Health and Social Behavior 38:21-27.

Kaplan, G.A., T.E. Seeman, R.D. Cohen, L.P. Knudsen, J. Guralnik. 1989. “Mortality among the elderly in Alameda County study." American Journal of Public Health 79:703-708.

Katz, S., A.B. Ford, R.W. Moskoweitz, B.A. Jackson, M.W. Jaffee. 1963. "Studies of illness in the aged. The index of ADL: A standardized measure of biological and psychosocial function." Journal of the American Medical Association 185:914919.

Kitagawa, E.M., P.M. Hauser. 1973. Differential Mortality in the United States: A Study in Socioeconomic Epidemiology. Cambridge, MA: Harvard University Press.

Knodel, J., M.B. Ofstedal, A.I. Hermalin. 2002. "The demographic, socioeconomic, and cultural context of the four study countries." In Hermalin A.I., ed., The WellBeing of the Elderly in Asia: A Four-Country Comparative Study. Ann Arbor, MI: The University of Michigan Press. Pp. 25-64.

Kuh, D., Y. Ben-Shlomo, eds. 1997. A Life Course Approach to Chronic Disease Epidemiology. Oxford: Oxford University Press. 
Lawton, M.P., E. Brody. 1969. "Assessment of older people: Self-maintaining and instrumental activities of daily living." The Gerontologist 9:179-186.

Lee, E.T., J.W. Wang. 2003. Statistical Methods for Survival Data Analysis. New York: John Wiley and Sons.

Liang, J., J. Bennett, N. Krause, E. Kobayashi, H. Kim, J.W. Brown, H. Akiyama, H. Sugisawa, A. Jain. 2002. "Old age mortality in Japan: Does the socioeconomic gradient interact with gender and age?" Journal of Gerontology: Social Sciences 57B(5):S294-S307.

Liang, J., J.F. McCarthy, A. Jain, N. Krause, J.M. Bennett, S. Gu. 2000. "Socioeconomic gradient in old age mortality in Wuhan, China." Journal of Gerontology: Social Sciences 55B(4): S222-S233.

Liaw, K.M., C.J. Chen. 1998. "Mortality attributable to cigarette smoking in Taiwan: A 12-year follow-up study." Tobacco Control 7:141-148.

Liu, X., A.I. Hermalin, Y.L. Chuang. 1998. "The effect of education on mortality among older Taiwanese and its pathways." Journal of Gerontology: Social Sciences 53B(2):S71-S82.

Lopez, A.D., G. Caselli, T. Valkonen, eds. 1995. Adult Mortality in Developed Countries: From Description to Explanation. Oxford: Clarendon Press.

Manton, K.G., E.S. Stallard, M.A. Woodbury, J.E. Dowd. 1994. “Time-varying covariates in models of human mortality and aging: Multidimensional generalizations of the Gompertz." Journal of Gerontology: Biological Sciences 49:B169-B190.

Mostafa, G., J.K. Van Ginneken. 2000. "Trends in and determinants of mortality in the elderly population of Matlab, Bangladesh." Social Science and Medicine 50:763771.

Mueller, L.D., T.J. Nusbaum, M.R. Rose. 1995. 'The Gompertz equation as a predictive tool in demography." Experimental Gerontology 30:553-569.

Nagi, S.Z. 1965. "Some conceptual issues in disability and rehabilitation." In M.B. Sussman, ed., Sociology and Rehabilitation. Washington, D.C.: American Sociological Association. Pp. 100-113. 
— 1991. "Disability concepts revisited: Implications for prevention." In A.M. Pope and AR Tarlov, eds., Disability in America: Toward a National Agenda for Prevention. Washington, D.C.: National Academy Press. Pp. 309-327.

Newhouse, J.P. and the Insurance Experiment Group. 1993. Free for All? Lessons From the RAND Health Insurance Experiment. Cambridge: Harvard University Press.

Preston, S.H., P. Taubman. 1994. "Socioeconomic differences in adult mortality and health status." In L.G. Martin and S.H. Preston, eds., Demography of Aging. Washington, D.C.: National Academy Press.

Rantanen, T., T. Harris, S.G. Leveille, M. Visser, D. Foley, K. Masaki, J.M. Guralnik. 2000. "Muscle strength and body mass index as long-term predictors of mortality in initially healthy men." Journal of Gerontology: Medical Sciences 55A: M168-M173.

United Nations. 2002. World Population Ageing 1950-2050. New York: United Nations.

Valkonen, T. 1989. "Adult mortality and level of education: A comparison of six countries.” In J. Fox, ed., Health Inequalities in European Countries. Aldershot, UK: Gower. Pp. 142-160.

Waldron, I. 1986. "What do we know about causes of sex differences in mortality? A review of the literature." Population Bulletin of the United Nations No. 18-1985.

Wilson, D.L. 1994. "The analysis of survival (mortality) data: Fitting Gompertz, Weibull, and logistic functions." Mechanisms of Ageing and Development 74:15-33.

Zimmer, Z., L.G. Martin, M.C. Chang. 2002. "Changes in functional limitation and survival among older Taiwanese, 1993, 1996, and 1999." Population Studies $56: 265-276$. 


\section{POLICY RESEARCH DIVISION WORKING PAPERS}

Recent back issues available at www.popcouncil.org/publications/wp/prd/rdwplist.html.

144 John Bongaarts, "Household size and composition in the developing world."

145 John B. Casterline, Zeba A. Sathar, and Minhaj ul Haque, "Obstacles to contraceptive use in Pakistan: A study in Punjab."

146 Zachary Zimmer, Albert I. Hermalin, and Hui-Sheng Lin, "Whose education counts? The impact of grown children's education on the physical functioning of their parents in Taiwan."

147 Philomena Nyarko, Brian Pence, and Cornelius Debpuur, "Immunization status and child survival in rural Ghana."

*148 John Bongaarts and Zachary Zimmer, "Living arrangements of older adults in the developing world: An analysis of DHS household surveys."

149 Markos Ezra, "Ecological degradation, rural poverty, and migration in Ethiopia: A contextual analysis."
150 Cynthia B. Lloyd, Sahar El Tawila, Wesley H. Clark, and Barbara S. Mensch, "Determinants of educational attainment among adolescents in Egypt: Does school quality make a difference?"

*151 Barbara S. Mensch, Paul C. Hewett, and Annabel Erulkar, "The reporting of sensitive behavior among adolescents: A methodological experiment in Kenya."

152 John Bongaarts, "The end of the fertility transition in the developed world."

*153 Mark R. Montgomery, Gebre-Egziabher Kiros, Dominic Agyeman, John B. Casterline, Peter Aglobitse, and Paul Hewett, "Social networks and contraceptive dynamics in southern Ghana."

*154 Paul C. Hewett and Mark R. Montgomery, "Poverty and public services in developing-country cities."

* No longer available as a printed publication. Download electronic file from website only. 
155 Zachary Zimmer, Linda G. Martin, and Ming-Cheng Chang, "Changes in functional limitations and survival among the elderly in Taiwan: 1993, 1996, and 1999."

156 John Bongaarts and Griffith Feeney, "How long do we live?"

157 Zachary Zimmer and Sovan Kiry Kim, "Living arrangements and socio-demographic conditions of older adults in Cambodia."

158 Geoffrey McNicoll, "Demographic factors in East Asian regional integration."

159 Carol E. Kaufman, Shelley Clark, Ntsiki Manzini, and Julian May, "How community structures of time and opportunity shape adolescent sexual behavior in South Africa."

*160 Julia Dayton and Martha Ainsworth, "The elderly and AIDS: Coping strategies and health consequences in rural Tanzania."

161 John Bongaarts, "The end of the fertility transition in the developing world."
162 Naomi Rutenberg, Carol E. Kaufman, Kate Macintyre, Lisanne Brown, and Ali Karim, "Pregnant or positive: Adolescent childbearing and HIV risk in South Africa."

163 Barbara S. Mensch, Wesley H. Clark, and Dang Nguyen Anh, "Premarital sex in Vietnam: Is the current concern with adolescent reproductive health warranted?"

164 Cynthia B. Lloyd, Cem Mete, and Zeba A. Sathar, "The effect of gender differences in primary school access, type, and quality on the decision to enroll in rural Pakistan."

165 Kelly Hallman, Agnes R. Quisumbing, Marie Ruel, and Bénédicte de la Brière, "Childcare, mothers' work, and earnings: Findings from the urban slums of Guatemala City."

*166 Carol E. Kaufman and Stavros E. Stavrou, “'Bus fare, please': The economics of sex and gifts among adolescents in urban South Africa."

*167 Dominic K. Agyeman and John B. Casterline, "Social organization and reproductive behavior in southern Ghana."

\footnotetext{
* No longer available as a printed publication. Download electronic file from website only.
} 
168 Paul C. Hewett, Annabel S. Erulkar, and Barbara S. Mensch, "The feasibility of computer-assisted survey interviewing in Africa: Experience from two rural districts in Kenya."

169 Zachary Zimmer and Julia Dayton, "The living arrangements of older adults in sub-Saharan Africa in a time of HIV/AIDS."

170 Ravai Marindo, Steve Pearson, and John B. Casterline, "Condom use and abstinence among unmarried young people in Zimbabwe: Which strategy, whose agenda?"

171 Sajeda Amin and Nagah H. AlBassusi, "Wage work and marriage: Perspectives of Egyptian working women."

172 Zachary Zimmer, Napaporn Chayovan, Hui-Sheng Lin, and Josefina Natividad, "How indicators of socioeconomic status relate to physical functioning of older adults in three Asian societies."

173 Paul Demeny, "Population policy: A concise summary."

174 Geoffrey McNicoll, "Population and development: An introductory view."

175 James F. Phillips, Tanya C. Jones, Frank K. Nyonator, and Shruti Ravikumar, "Evidence-based develop- ment of health and family planning programs in Bangladesh and Ghana."

176 Cynthia B. Lloyd and Paul C. Hewett, "Primary schooling in sub-Saharan Africa: Recent trends and current challenges."

177 John Bongaarts, "Completing the fertility transition in the developing world: The role of educational differences and fertility preferences."

178 Elizabeth F. Jackson, Patricia Akweongo, Evelyn Sakeah, Abraham Hodgson, Rofina Asuru, and James F. Phillips, "Women's denial of having experienced female genital cutting in northern Ghana: Explanatory factors and consequences for analysis of survey data."

179 John Bongaarts and Griffith Feeney, "Estimating mean lifetime."

180 Frank K. Nyonator, J. Koku AwoonorWilliams, James F. Phillips, Tanya C. Jones, and Robert A. Miller, "The Ghana Community-based Health Planning and Services Initiative: Fostering evidence-based organizational change and development in a resource-constrained setting."

181 Zachary Zimmer, Linda G. Martin, and Hui-Sheng Lin, "Determinants of old-age mortality in Taiwan." 